\title{
Retreatment of flat-oval root canals with a self-adjusting file: An SEM study
}

\author{
Ali KELEŞ ${ }^{1}$, Neslihan ŞIMŞEK ${ }^{1}$, Hatice ALÇIN¹, Fuat AHMETOGLU¹ and Saim YOLOGLU² \\ ${ }^{1}$ Department of Endodontics, Faculty of Dentistry, Inönü University, Malatya, Turkey \\ ${ }^{2}$ Department of Biostatistics, Faculty of Medicine, Inönü University, Malatya, Turkey \\ Corresponding author, Ali KELEŞ; E-mail: ali.keles@inonu.edu.tr
}

\begin{abstract}
This study evaluated the efficacy of the Self-Adjusting File (SAF) in removing the root filling remnants and smear layer left in oval shaped root canals after using R-Endo retreatment files, by using scanning electron microscopy (SEM). Forty eight maxillary premolars were prepared and the SAF was used in all of the teeth to remove debris and smear layer. Sixteen teeth were used as control and the other 32 teeth were obturated and randomly assigned to two groups according to the retreatment procedures: R-Endo retreatment files and R-Endo retreatment files+SAF. Then, all roots were split longitudinally for SEM evaluation. Using SEM pictures, the number of dentinal tubules and the surface area covered by filling remnants were evaluated. None of the techniques removed root filling remnants and smear layer completely. Additional use of SAF after the retreatment procedures may improve root canal cleanliness in the coronal and middle thirds of oval root canals.
\end{abstract}

Keywords: Smear layer, Filling residue, SAF, Retreatment, SEM

\section{INTRODUCTION}

The main goals of endodontic treatment are to clean and disinfect the root canal system and to seal the system in three dimensions to prevent recontamination ${ }^{1}$. Initial endodontic treatment has been reported to be successful in achieving these goals ${ }^{2,3)}$, but failure may occur after treatment ${ }^{4,5}$. Such failures are most often caused by microorganisms, which either survived the initial treatment procedures or invaded the root canal at later stages ${ }^{6)}$. The aim of any retreatment procedure is the removal of previous root filling material to allow for the disinfection and obturation of the root canal ${ }^{7,8)}$. However, recent studies have indicated that a significant amount of root filling residue remains on the canal wall after retreatment ${ }^{9,10)}$.

Oval shaped canals represent a critical challenge for any root canal cleaning, shaping ${ }^{11-13)}$, or retreatment protocol $^{14-16)}$. Numerous studies have reported that hand and rotary instrumentation of oval shaped canals leave unprepared buccal and lingual extensions or recesses ${ }^{17-20)}$. The self-adjusting file system (SAF) has been devised to sidestep certain limitations of rotary instruments ${ }^{21-23)}$. Studies have demonstrated that the SAF protocol is significantly more efficient in debriding ${ }^{11,12,20,24)}$ and removing residual gutta percha from oval root canals $^{14-16)}$. Previously published articles evaluated the amount of residual filling material after retreatment using microcomputed tomography ${ }^{14,16)}$, however, to our knowledge, there is no published reports about efficacy of SAF on smear layer and debris after retreatment procedure. The aim of this study was to utilize SEM to evaluate the efficacy of removing the smear layer and remnants from oval root canals after retreatment using $\mathrm{R}$-Endo retreatment files with or without the additional use of SAF.

Received Feb 25, 2014: Accepted Jul 9, 2014

doi:10.4012/dmj.2014-054 JOI JST.JSTAGE/dmj/2014-054

\section{MATERIALS AND METHODS}

After approval from the ethics committee (protocol \#218/2012), 48 maxillary premolars extracted for periodontal or orthodontic reasons were selected. Each tooth exhibited the following features: one straight root with an oval shaped canal, fully formed apices, the absence of a root canal filling, resorption or calcifications. The roots were radiographed in buccolingual and mesiodistal projections to categorize them and to detect any possible obstruction. The ratio of the buccolingual to the mesiodistal diameter of the canal was calculated at $5 \mathrm{~mm}$ and $8 \mathrm{~mm}$ from the radiographic apex. When the buccolingual diameter was 2 times larger than that of the mesiodistal diameter at $5 \mathrm{~mm}$ and 3 times larger at $8 \mathrm{~mm}$, the canals were classified as oval-shaped. The teeth were decoronated with a diamond bur at the cementoenamel junction using a high-speed handpiece.

A size $10 \mathrm{~K}$-file was inserted into the canal until it was visible at the apical foramen, and the working length (WL) was determined to be $1.0 \mathrm{~mm}$ shorter than this length. Each root canal was serially enlarged with NiTi rotary files (Revo-S, Micro-Mega, Besançon, France) sizes \#25, 0.06 taper (SC1), \#25, 0.04 taper (SC2), and \#25, 0.06 taper (SU) in a crown-down manner. For apical preparation, rotary instruments (Revo-S; MicroMega) were used in the following sizes: \#30, 0.06 taper (AS30), \#35, 0.06 taper (AS35), and \#40, 0.06 taper (AS40). Finally, apical enlargement was completed with a size 45 K-file (Mani, Inc., Tochigi, Japan). During all procedures, the canals were flushed with $2 \mathrm{~mL}$ of $5 \%$ $\mathrm{NaOCl}$ between each instrument.

Studies have reported that the SAF provides the best root canal shaping and that it removes more of the smear layer and debris in oval root canals ${ }^{20,21)}$. The SAF system (ReDent Nova, Raanana, Israel), in conjunction with an NSK low speed handpiece, was used to remove 
the smear layer from the root canal walls. The handpiece was connected to the RDT3-NX head (ReDent Nova), which generates 5,000 in-and-out vibrations per min and has an amplitude of $0.4 \mathrm{~mm}$. Following the manufacturer's recommendations, the SAF instrumentation was carried out for $4 \mathrm{~min}$ and 3 cycles. The canals were irrigated with $5 \% \mathrm{NaOCl}$ for $2 \mathrm{~min}$ using the VATEA system (ReDent Nova) at a flow rate of $5 \mathrm{~mL} / \mathrm{min}$. With the aim of removing the smear layer, 1 min of 15\% EDTA irrigation and instrumentation was followed by a final $5 \% \mathrm{NaOCl}$ irrigation and instrumentation for $1 \mathrm{~min}$. Then, a final flush was performed with $2 \mathrm{~mL} / \mathrm{min} 15 \%$ EDTA, followed by $2 \mathrm{~mL} \mathrm{5 \%} \mathrm{NaOCl}$. All root canals were dried with paper points. A new $2.0 \mathrm{~mm}$ diameter SAF file was used for each canal, and the instrument was applied with a pecking motion, which allowed the unrestricted file to rotate. After then, 16 roots were randomly selected. These root canals were not obturated and this group served as control.

Then, 32 root canals were filled via the vertical condensation technique (Dia-Gun Obturation System, North Fraser Way, Burnaby, BC, Canada). AH Plus (DeTrey- Dentsply, Konstanz, Germany) was used as a sealer. The roots were radiographed in the buccolingual and mesiodistal directions to confirm the adequacy of the filling. If voids were observed in the filling mass, the specimen was replaced. The samples were then stored in $100 \%$ humidity at $37^{\circ} \mathrm{C}$ for 3 weeks to allow for the complete setting of the sealer. The specimens were randomly assigned to 2 groups $(n=16)$ according to the retreatment procedures.

\section{Retreatment}

In the groups, R-Endo (Micro-Mega, Besançon, France) retreatment files were used as recommended by the manufacturer in a gentle in and out motion with a rotary electric motor (W\&H, Bürmoos, Austria) at a speed of 340 rpm. A total of $3 \mathrm{~mm}$ of root filling material was removed from the cervical part of the canal using Re (\#25, 0.12 taper) files. R1 (\#25, 0.08 taper) was used in the coronal third, R2 (\#25, 0.06 taper) was used in the middle third, and R3 (\#25, 0.04 taper) was carried to the working length with circumferential filing action. The canals were irrigated regularly after each instrument with 2.5 $\mathrm{mL}$ of $5 \% \mathrm{NaOCl}$. The instruments were replaced after 5 canals, and the retreatment procedure was considered to be complete when the working length was reached, no material was observed between the flutes of the files, and the irrigating solution appeared to be clear of debris. All of the root canals in R-Endo group were irrigated with 5 $\mathrm{mL}$ of $15 \%$ EDTA and $5 \mathrm{~mL}$ of $5 \% \mathrm{NaOCl}$ and were dried with paper points.

In R-Endo+SAF group, after the described procedure, the additional use of SAF (ReDent-Nova, Ra'anana, Israel) was performed to remove the filling residue left in the canal. A 2.0-mm-diameter SAF was operated in the canal using an RDT3-NX (ReDent-Nova) head adapted with a low-speed handpiece (NSK, Tokyo, Japan) at $5,000 \mathrm{rpm}$ with an amplitude of $0.4 \mathrm{~mm}$. The SAF was connected to a VATEA system irrigator and used in a pecking motion for $2 \mathrm{~min}$. Continuous irrigation at a flow rate of $5 \mathrm{~mL} / \mathrm{min}$ was applied with $15 \%$ EDTA for 1 min followed by $5 \% \mathrm{NaOCl}$ for 1 min during the SAF instrumentation. A new SAF file was used for each root canal and all canals were dried with paper points.

Thus, all of the controllable factors apart from the retreatment procedures were standardized as much as possible. In addition, to achieve a certain degree of uniformity and to reduce interoperator variables, all experimental procedures were conducted by the same operator.

\section{SEM preparation and evaluation methods}

All the teeth in control, R-Endo and R-Endo+SAF groups were grooved on the buccal and lingual surfaces with a diamond disc and split longitudinally. Two halves of the roots were examined using SEM (LEO EVO 40 Cambridge). After a general evaluation of the root canal walls from the apex to the coronal portion, 5 SEM photographs of the smear layer were obtained at a magnification of $2,000 \times, 3$ of the center of the coronal, middle, and apical thirds (CC, MC, and A, respectively) and 2 of the periphery of the coronal and middle thirds (CP and MP, respectively) (Fig. 1). These 5 observation positions of smear layer are presented in Fig. 2. SEM photographs of the debris in the coronal, middle, and apical thirds were also obtained at $100 \times$ (Fig. 2). The SEM images were rated in blinded manner using a modified predefined scale (Table 1).

\section{Statistical analysis}

MedCalc statistical software (www.medcalc.org) was used for data analysis. All data are shown as mean \pm standard deviation (SD). Normality of distribution for continuous variables in the groups was determined by the Shapiro-Wilk test. The variables did not show normal distribution $(p<0.05)$. Therefore, the KruskalWallis test was used to compare variables among the studied groups. A value of $p<0.05$ was considered significant.

\section{RESULTS}

\section{Surface properties}

The mean and SD values for the surface profile scores of the coronal, middle, and apical thirds of the root canals are presented in Table 2 . There were statistically significant differences among these groups in the thirds of the root canal $(p<0.05)$. In the coronal and middle thirds, there were no statistically significant differences between the control and R-Endo+SAF groups ( $p>0.05)$. In these thirds, additional use of SAF may improve the cleanliness of root canals. In the apical third there was no statistically significant differences between R-Endo and R-Endo+SAF groups ( $p>0.05)$.

\section{Smear layer}

The mean and SD values for the removal of smear layer scores of each selected area are shown in Table 3. None of the retreatment techniques removed the smear layer 

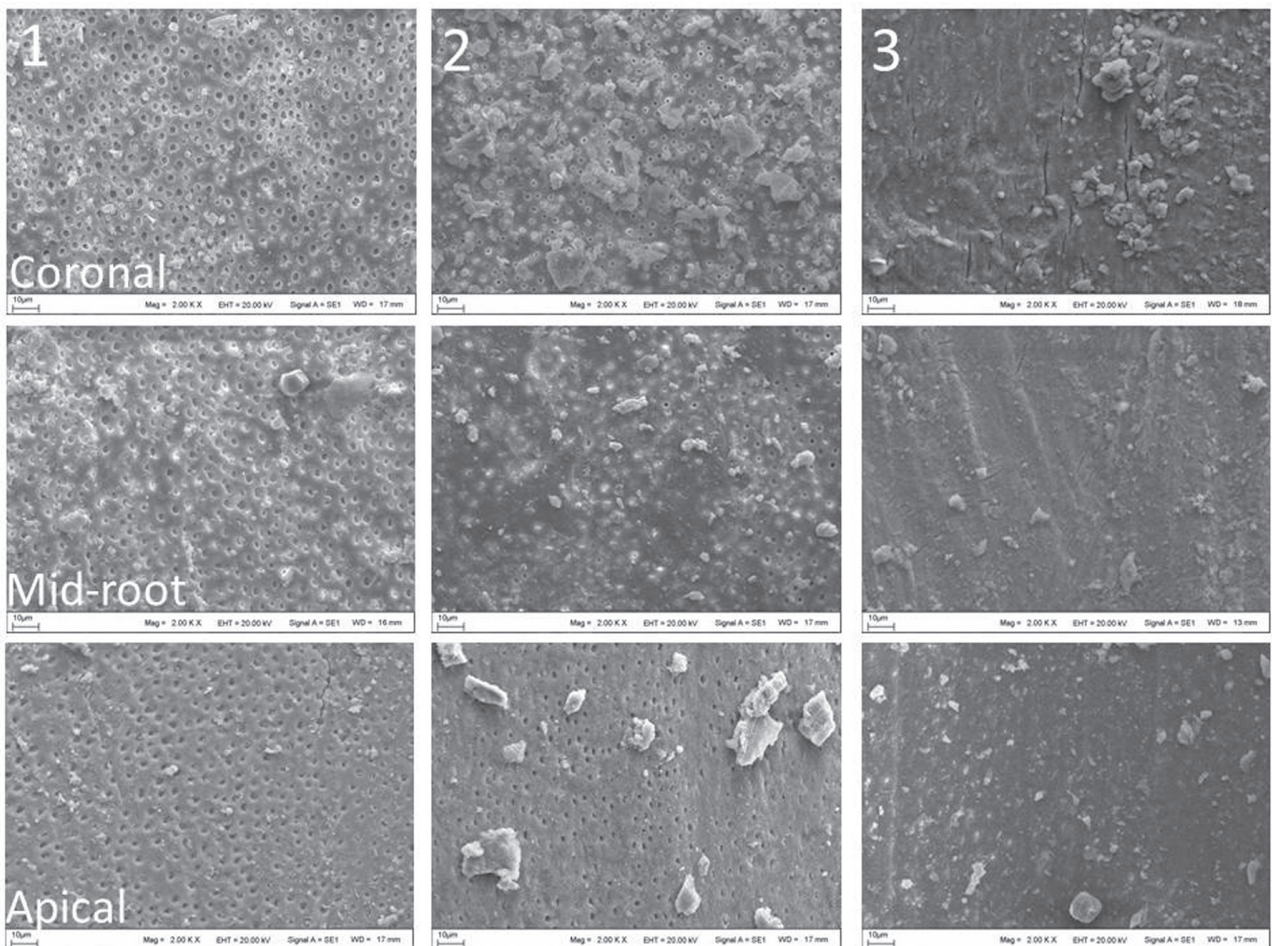

Fig. 1 Representative SEM images of smear layer scores $(1,2,3)$. (original magnification: 2,000×).
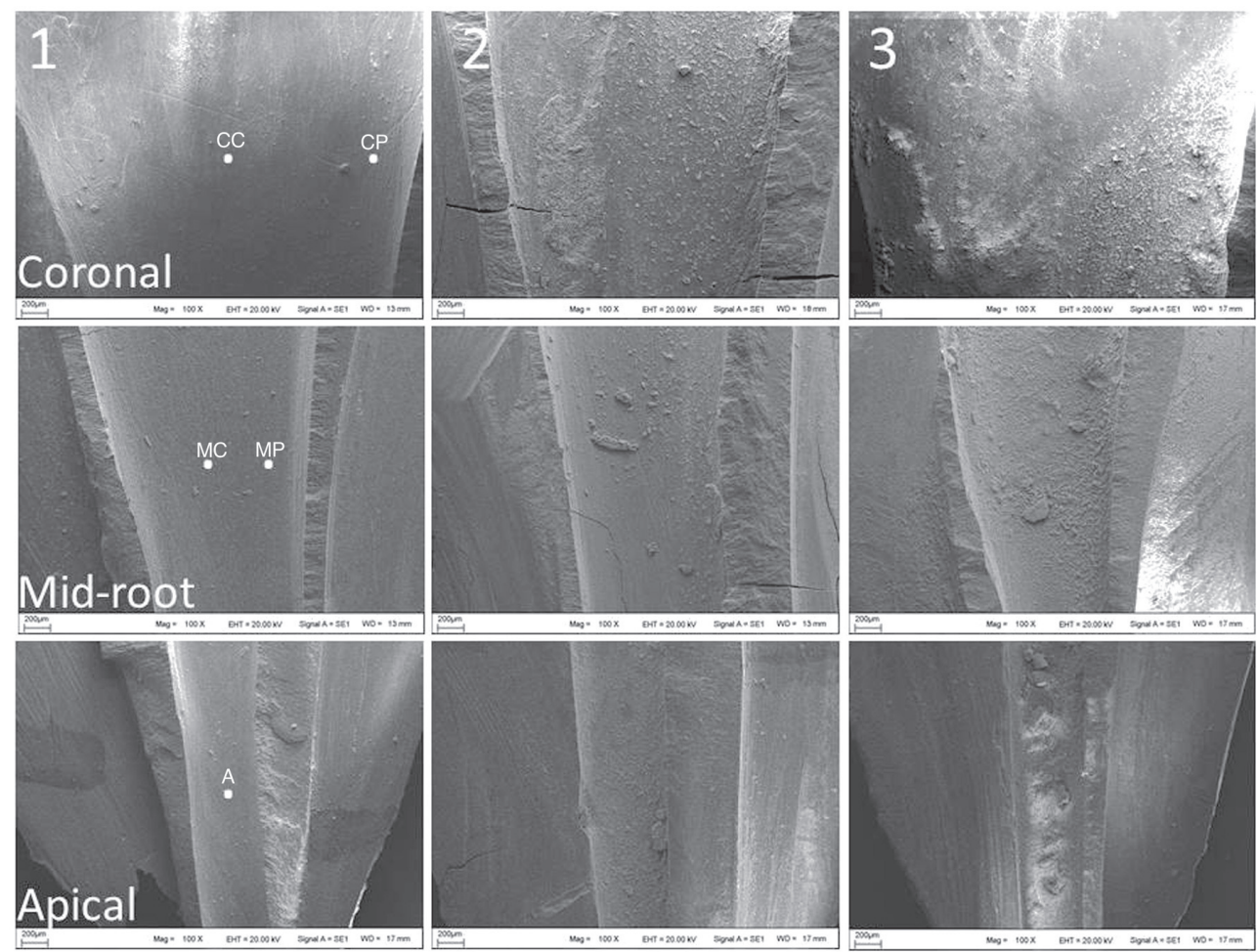

Fig. 2 Representative SEM images of surface profile scores $(1,2,3)$. White spots in first column show selected areas. (original magnification: 100×). 
Table 1 Scale of values assigned to the 2 different parameters evaluated

\begin{tabular}{lccc}
\hline \multicolumn{1}{c}{1} & 2 & 3 \\
\hline Smear layer & $\begin{array}{c}\text { The majority of tubules exposed } \\
\text { and free from smear layer. }\end{array}$ & $\begin{array}{c}\text { Smear layer present. The } \\
\text { minority of tubules visible. }\end{array}$ & $\begin{array}{c}\text { Homogenous smear layer present above } \\
\text { all dentin. Dentinal tubules not visible. }\end{array}$ \\
Surface profile & Absence of irregularities & $\begin{array}{c}\text { Isolated irregularities } \\
\text { present in limited area. }\end{array}$ & $\begin{array}{c}\text { Irregularities and noninstrumented } \\
\text { dentin present. }\end{array}$ \\
\hline
\end{tabular}

Table 2 The mean and SD values of surface profile scores of root canal thirds in the groups

\begin{tabular}{|c|c|c|c|c|}
\hline & $\begin{array}{c}\text { Control } \\
\text { Mean } \pm \text { SD }\end{array}$ & $\begin{array}{c}\text { R-Endo } \\
\text { Mean } \pm \text { SD }\end{array}$ & $\begin{array}{l}\text { R-Endo+SAF } \\
\text { Mean } \pm \text { SD }\end{array}$ & \\
\hline Coronal & $1.44^{\mathrm{a}} \pm 0.57$ & $2.00^{\mathrm{a}} \pm 0.57$ & $1.63^{\mathrm{a}} \pm 0.79$ & $p=0.0018$ \\
\hline Middle & $1.25^{\mathrm{a}} \pm 0.44$ & $2.09^{a b} \pm 0.73$ & $1.41^{\mathrm{a}} \pm 0.62$ & $p<0.0001$ \\
\hline \multirow[t]{2}{*}{ Apical } & $1.44^{\mathrm{a}} \pm 0.72$ & $2.44^{\mathrm{bc}} \pm 0.71$ & $2.31^{\mathrm{b}} \pm 0.78$ & $p<0.0001$ \\
\hline & $p=0.1919$ & $p=0.019$ & $p<0.0001$ & \\
\hline
\end{tabular}

Values in bold letter mean statistical significant difference among the groups.

Different superscript letters in the same column mean statistical significant difference within the group.

Table 3 The mean and SD values of smear layer removal scores of root canal areas in the groups

\begin{tabular}{lccccc}
\hline & $\begin{array}{c}\mathrm{CC} \\
\text { Mean } \pm \text { SD }\end{array}$ & $\begin{array}{c}\mathrm{CP} \\
\text { Mean } \pm \text { SD }\end{array}$ & $\begin{array}{c}\text { MC } \\
\text { Mean } \pm \text { SD }\end{array}$ & \multicolumn{1}{c}{$\begin{array}{c}\text { MP } \\
\text { Mean } \pm \text { SD }\end{array}$} & $\begin{array}{c}\text { Mean } \pm \text { SD } \\
\text { Control }\end{array}$ \\
R-Endo+SAF & $2.06^{\mathrm{a}} \pm 0.88$ & $1.96^{\mathrm{a}} \pm 0.8$ & $1.19^{\mathrm{a}} \pm 0.41$ & $2.17^{\mathrm{a}} \pm 0.4$ & $1.56^{\mathrm{a}} \pm 0.62$ \\
R-Endo & $2.34^{\mathrm{b}} \pm 0.83$ & $2.5^{\mathrm{b}} \pm 0.67$ & $2.28^{\mathrm{b}} \pm 0.81$ & $2.21^{\mathrm{b}} \pm 0.84$ & $2.5^{\mathrm{b}} \pm 0.76$ \\
& $2.59^{\mathrm{b}} \pm 0.67$ & $2.66^{\mathrm{b}} \pm 0.65$ & $2.69^{\mathrm{c}} \pm 0.54$ & $2.63^{\mathrm{c}} \pm 0.61$ & $2.72^{\mathrm{b}} \pm 0.52$ \\
\hline & $p<0.0001$ & $p<0.0001$ & $p<0.0001$ & $p<0.0001$ & $p<0.0001$ \\
\hline
\end{tabular}

Different superscript letters in the same column mean statistical significant difference within the group.

in the coronal, middle, or apical thirds completely. However, R-Endo+SAF protocol was more effective for removing smear layer than the R-Endo protocol in the MC and MP areas $(p<0.05)$. No statistically differences were found between the groups in the other areas $(p>0.05)$.

\section{DISCUSSION}

There is a general belief that the success rates for endodontic retreatment are lower than those for primary treatment ${ }^{25)}$. Although it may not be proven that residual root canal filling materials are responsible for retreatment failure, the successful removal of gutta percha and sealer is an important step in uncovering the remaining necrotic tissue or bacteria that give rise to persistent disease and reinfection of the root canal system $^{26)}$. Removing root canal fillings is a difficult procedure, and none of the retreatment methods that were reported could render all canals completely free of root filling residue.

Canals have different shapes in cross-section. In this study, a single canal with high ovality in maxillary premolar teeth were used ${ }^{27)}$. The canal's shape may render it difficult to clean properly. The SAF makes more root canal wall contact possible relative to other rotary files in oval root canals ${ }^{24}$. Recent studies reported that the SAF has potential in the later stages of the removal of root canal filling ${ }^{14,28,29)}$. The SAF alone cannot be considered to be an instrument capable of removing the bulk of root filling material ${ }^{29)}$

The use of SEM to evaluate canal filling remnants or debris has been questioned because of the different magnifications used in different studies and the different areas selected by the investigator ${ }^{26)}$. Generally, SEM is used for the examination of dentinal tubules with respect to the presence of filling materials ${ }^{26,30,31)}$. In this study, a magnification of $100 \times$ was used to evaluate 
the surface profiles, and a magnification of 2,000× was used to evaluate the smear layer. Operator bias was limited by randomizing the teeth numbers during the SEM imaging, and the resulting photographs were then evaluated.

This study found that, R-Endo+SAF protocol left less remnants than the use of R-Endo alone (Table 2). In the coronal and middle thirds, R-Endo+SAF protocol was able to remove the remnants which were occurred after use of R-Endo files $(p<0.05)$. But, in the apical third these remnants could not be removed. The SEM analysis showed more remnants in the apical third than the other thirds of the root canal, for the R-Endo+SAF protocol $(p<0.05)$. This finding is in accordance with the findings of previous studies ${ }^{31-33)}$.

$\mathrm{R}$-Endo+SAF protocol was not able to remove the smear layer completely which were occurred after use of R-Endo files (Table 3). Furthermore, except the MC and MP areas, there was no statistically significant difference between R-Endo and R-Endo+SAF protocol in the other areas $(p>0.05)$. In the middle third, $\mathrm{R}$-Endo+SAF protocol was able to remove a number of smear layer $(p<0.05)$ but, it was not enough to arrive non-filled control group. This result is in contrast with another study that used a rotary file and the SAF protocol to remove the root canal filling ${ }^{29)}$. This finding might be due to a different study design, including the evaluation methods and the ovality of the root canal. Solomonov et al. ${ }^{14)}$ and Keleş et $a l .{ }^{16)}$ reported that a rotary system combined with the SAF removed a greater amount of root canal filling remnants than a rotary system alone. However, those studies did not include information on the parts of the root canals. Ahmetoğlu et al. ${ }^{34)}$ reported that the SAF had same efficiency in the thirds of root canal. Also, they found no statistically differences between conventional irrigation and SAF in middle and apical thirds when used to remove calcium hydroxide from the root canals. In this study, the greater effectiveness of the R-Endo files and the SAF protocol in the middle third of the root canal can be attributed to the ovality and the width of the root canal, both of which made it possible to use the SAF. It has been reported that the SAF is less effective when the diameter of the canal is larger than the diameter of the $\mathrm{SAF}^{35)}$. In the present study, despite the use of an SAF with a diameter of $2.0 \mathrm{~mm}$, the SAF was still smaller than the inner space of the coronal third of the root canal, and the SAF did not touch all regions of the root canal walls both control and R-Endo+SAF groups. Although the operator used the SAF under pressure in the buccolingual direction to obtain more contact with the root canal walls, the desired pressure could not be achieved due to the more flexible structure of the SAF.

A high ratio of oval root canals can be found in the apical third of the single root canal of the maxillary premolar ${ }^{27,36)}$. Wider instrumentation has been recommended in these teeth to remove bacteria and infected dentin and to achieve a round canal shape in this third ${ }^{36,37)}$. Studies have suggested that size \#40 to \#70 files should be used for effective apical preparation. In this study, the final apical preparation was made with a size \#45 file ${ }^{36,38)}$. The SEM analysis revealed more debris left in the apical third, regardless of the retreatment protocol $(p<0.05)$. This result may be related to the size of the master apical file selected in the R-Endo group. In the R-Endo group, an R3 R-Endo retreatment file with a size 25 tip was used in the apical third. A previous study reported that using a round shaped retreatment file with the same size of MAF was more effective in cleaning the apical third ${ }^{31)}$. Paque and Peters ${ }^{24)}$ reported that approximately $40 \%$ of the uninstrumented area remained in the apical third when the SAF was used in oval root canals. Although the size of the MAF used in the present study was close to the reported size of the SAF used in other studies ${ }^{12,23)}$, the results of this study revealed that the additional use of the SAF did not facilitate the removal of debris from the apical third.

\section{CONCLUSION}

Within the limitations of this ex vivo study, neither retreatment protocol was able to render all canals free of root filling remnants or the smear layer. In the coronal and middle third, the SAF increased the amount of filling remnants removed from the oval root canal compared with the R-Endo retreatment instruments alone. On the other hand, additional use of SAF after R-Endo files was not able to remove smear layer completely and not improve root canal cleanliness, except the middle third of root canal. The removal of root canal filling debris and smear layer from the large oval root canal remains difficult.

\section{ACKNOWLEDGMENT}

The authors deny any conflicts of interest. This study was supported İnönü University Committee of Research Projects.

\section{REFERENCE}

1) Fleming CH, Litaker MS, Alley LW, Eleazer PD. Comparison of classic endodontic techniques versus contemporary techniques on endodontic treatment success. J Endod 2010; 36: 414-418.

2) Friedman S, Abitbol S, Lawrence HP. Treatment outcome in endodontics: the Toronto Study. Phase 1: initial treatment. J Endod 2003; 29: 787-793.

3) Kojima K, Inamoto K, Nagamatsu K, Hara A, Nakata K, Morita I, Nakagaki H, Nakamura H. Success rate of endodontic treatment of teeth with vital and nonvital pulps. A meta-analysis. Oral Surg Oral Med Oral Pathol Oral Radiol Endod 2004; 97: 95-99.

4) Torabinejad M, Corr R, Handysides R, Shabahang S. Outcomes of nonsurgical retreatment and endodontic surgery: a systematic review. J Endod 2009; 35: 930-937.

5) de Chevigny C, Dao TT, Basrani BR, Marquis V, Farzaneh M, Abitbol S, Friedman S. Treatment outcome in endodontics: the Toronto study_phase 4: initial treatment. J Endod 2008; 34: 258-263.

6) Setzer FC, Boyer KR, Jeppson JR, Karabucak B, Kim S. Longterm prognosis of endodontically treated teeth: a retrospective analysis of preoperative factors in molars. J Endod 2011; 37: 21-25. 
7) Stabholz A, Friedman S. Endodontic retreatment-case selection and technique. Part 2: Treatment planning for retreatment. J Endod 1988; 14: 607-614.

8) Friedman S, Stabholz A, Tamse A. Endodontic retreatmentcase selection and technique. 3. Retreatment techniques. J Endod 1990; 16: 543-549.

9) Tasdemir T, Er K, Yildirim T, Celik D. Efficacy of three rotary NiTi instruments in removing gutta-percha from root canals. Int Endod J 2008; 41: 191-196.

10) Tasdemir T, Yildirim T, Celik D. Comparative study of removal of current endodontic fillings. J Endod 2008; 34: 326329.

11) De-Deus G, Souza EM, Barino B, Maia J, Zamolyi RQ, Reis C, Kfir A. The self-adjusting file optimizes debridement quality in oval-shaped root canals. J Endod 2011; 37: 701-705.

12) Versiani MA, Pecora JD, de Sousa-Neto MD. Flat-oval root canal preparation with self-adjusting file instrument: a microcomputed tomography study. J Endod 2011; 37: 1002-1007.

13) Wu MK, Kast'akova A, Wesselink PR. Quality of cold and warm gutta-percha fillings in oval canals in mandibular premolars. Int Endod J 2001; 34: 485-491.

14) Solomonov M, Paque F, Kaya S, Adiguzel O, Kfir A, YigitOzer S. Self-adjusting files in retreatment: A high-resolution micro-computed tomography study. J Endod 2012; 38: 12831287.

15) Zmener O, Pameijer CH, Banegas G. Retreatment efficacy of hand versus automated instrumentation in oval-shaped root canals: an ex vivo study. Int Endod J 2006; 39: 521-526.

16) Keles A, Alcin H, Kamalak A, Versiani MA. Oval-shaped canal retreatment with self-adjusting file: a micro-CT study. Clin Oral Investig 2014; 18: 1147-1153.

17) Alves FR, Almeida BM, Neves MA, Moreno JO, Rocas IN, Siqueira JF. Disinfecting oval-shaped root canals: effectiveness of different supplementary approaches. J Endod 2011; 37: 496-501.

18) Hilaly Eid GE, Wanees Amin SA. Changes in diameter, crosssectional area, and extent of canal-wall touching on using 3 instrumentation techniques in long-oval canals. Oral Surg Oral Med Oral Pathol Oral Radiol Endod 2011; 112: 688695.

19) Elayouti A, Chu AL, Kimionis I, Klein C, Weiger R, Lost C. Efficacy of rotary instruments with greater taper in preparing oval root canals. Int Endod J 2008; 41: 1088-1092.

20) Metzger Z, Teperovich E, Cohen R, Zary R, Paque F, Hulsmann M. The self-adjusting file (SAF). Part 3: removal of debris and smear layer-A scanning electron microscope study. J Endod 2010; 36: 697-702.

21) Hof R, Perevalov V, Eltanani M, Zary R, Metzger Z. The selfadjusting file (SAF). Part 2: mechanical analysis. J Endod 2010; 36: 691-696.

22) Metzger Z, Teperovich E, Zary R, Cohen R, Hof R. The self-adjusting file (SAF). Part 1: respecting the root canal anatomy - a new concept of endodontic files and its implementation. J Endod 2010; 36: 679-690.

23) Metzger Z, Zary R, Cohen R, Teperovich E, Paque F. The quality of root canal preparation and root canal obturation in canals treated with rotary versus self-adjusting files: a threedimensional micro-computed tomographic study. J Endod 2010; 36: 1569-1573.

24) Paque F, Peters OA. Micro-computed tomography evaluation of the preparation of long oval root canals in mandibular molars with the self-adjusting file. J Endod 2011; 37: 517521.

25) Ng YL, Mann V, Gulabivala K. Outcome of secondary root canal treatment: a systematic review of the literature. Int Endod J 2008; 41: 1026-1046.

26) Horvath SD, Altenburger MJ, Naumann M, Wolkewitz M, Schirrmeister JF. Cleanliness of dentinal tubules following gutta-percha removal with and without solvents: a scanning electron microscopic study. Int Endod J 2009; 42: 1032-1038.

27) Wu MK, R'Oris A, Barkis D, Wesselink PR. Prevalence and extent of long oval canals in the apical third. Oral Surg Oral Med Oral Pathol Oral Radiol Endod 2000; 89: 739-743.

28) Voet KC, Wu MK, Wesselink PR, Shemesh H. Removal of gutta-percha from root canals using the self-adjusting file. J Endod 2012; 38: 1004-1006.

29) Abramovitz I, Relles-Bonar S, Baransi B, Kfir A. The effectiveness of a self-adjusting file to remove residual guttapercha after retreatment with rotary files. Int Endod J 2012; 45: 386-392.

30) Scelza MF, Coil JM, Maciel AC, Oliveira LR, Scelza P. Comparative SEM evaluation of three solvents used in endodontic retreatment: an ex vivo study. J Appl Oral Sci 2008; 16: 24-29.

31) Somma F, Cammarota G, Plotino G, Grande NM, Pameijer CH. The effectiveness of manual and mechanical instrumentation for the retreatment of three different root canal filling materials. J Endod 2008; 34: 466-469.

32) Ferreira JJ, Rhodes JS, Ford TR. The efficacy of gutta-percha removal using ProFiles. Int Endod J 2001; 34: 267-274.

33) Ezzie E, Fleury A, Solomon E, Spears R, He J. Efficacy of retreatment techniques for a resin-based root canal obturation material. J Endod 2006; 32: 341-344.

34) Ahmetoğlu F, Şimşek N, Keleş A, Ocak MS, Er K. Efficacy of self-adjusting file and passive ultrasonic irrigation on removing calcium hydroxide from root canals. Dent Mater $\mathrm{J}$ 2013; 32: 1005-1010.

35) Peters OA, Boessler C, Paque F. Root canal preparation with a novel nickel-titanium instrument evaluated with microcomputed tomography: canal surface preparation over time. J Endod 2010; 36: 1068-1072.

36) Hecker H, Bartha T, Lost C, Weiger R. Determining the apical preparation size in premolars: part III. Oral Surg Oral Med Oral Pathol Oral Radiol Endod 2010; 110: 118-124.

37) Card SJ, Sigurdsson A, Orstavik D, Trope M. The effectiveness of increased apical enlargement in reducing intracanal bacteria. J Endod 2002; 28: 779-783.

38) Kerekes K, Tronstad L. Morphometric observations on root canals of human premolars. J Endod 1977; 3: 74-79. 